\title{
Domain structure and function within the QUTA protein of Aspergillus nidulans: implications for the control of transcription
}

Ian Levesley, ${ }^{1}$ Giles H. Newton, ${ }^{2}$ Heather K. Lamb, ${ }^{2}$ Evert van Schothorst, ${ }^{1}$ Raymond W. M. Dalgleish, ${ }^{1}$ Anthony C. R. Samson, ${ }^{2}$ Clive F. Roberts ${ }^{1}$ and Alastair R. Hawkins ${ }^{2}$

Author for correspondence: Alastair R. Hawkins.Tel: +44 191222 7673. Fax: +44 1912227424. e-mail: a.r.hawkins@ncl.ac.uk

1 Department of Genetics, Adrian Building, University of Leicester, Leicester LE1 7RH, UK

2 Department of Biochemistry and Genetics, Catherine Cookson Building, New Medical School, University of Newcastle upon Tyne NE2 4HH, UK.
QUTA is a positively acting regulatory protein that regulates the expression of the eight genes comprising the quinic acid utilization gene (qut) gene cluster in Aspergillus nidulans. It has been proposed that the QUTA protein is composed of two domains that are related to the $\mathbf{N}$-terminal two domains dehydroquinate (DHQ) synthase and 5-enolpyruvyl shikimate-3-phosphate (EPSP) synthase - of the pentadomain AROM protein. The AROM protein is an enzyme catalysing five consecutive steps in the shikimate pathway, two of which are common to the qut pathway. A genetic and molecular analysis of non-inducible qutA mutants showed that all 23 mutations analysed map within the N-terminal half of the encoded QUTA protein. One dominant mutation (qutA382) introduces a stop codon at the boundary between the two domains that were identified on the basis of amino acid sequence alignments between the QUTA protein and the N-terminal two domains of the pentafunctional AROM protein. The truncated protein encoded by mutant qutA382 has DNA-binding ability but no transcription activation function. A second dominant mutation (in strain qutA214) is missense, changing 457E $\rightarrow K$ in a region of localized high negative charge and potentially identifies a transcription activation domain in the $\mathrm{N}$-terminus of the EPSP-synthase-like domain of the QUTA protein. A series of qualitative and quantitative Northern blot experiments with mRNA derived from wild-type and mutant qutA strains supported the view that the QUTA protein regulates the expression of the qut gene cluster, including the qutA gene which encodes it. A series of Western blot and zinc-binding experiments demonstrated that a putative zinc binuclear cluster motif located within the $\mathbf{N}$-terminus of the QUTA protein is able to bind zinc in vitro.

Keywords: transcription, autoregulation, transcription activation domain, zinc binding

\section{INTRODUCTION}

Aspergillus nidulans can utilize quinate as an alternate dispensable carbon source and the production of the three enzymes necessary to convert quinate to protocatechuate is induced by the presence of exogenously supplied

Abbreviations and enzyme designations: AROM, a pentadomain protein catalysing the conversion of 3-deoxy-D-arabino-heptulosonic 7phosphate to 5-eno/pyruvyl shikimate 3-phosphate; DHQ, dehydroquinate; DHQ synthase, dehydroquinate synthase (EC 4.6.1.3); dehydroquinase, EC 4.2.1.10; EPSP synthase, 5-enolpyruvyl shikimate-3-phosphate synthase (EC 2.5.1.19); GST, glutathione S-transferase; MC, metal- quinate. This induction of enzyme activity is sensitive to carbon catabolite repression, as the presence of glucose inhibits enzyme production (Whittington et al., 1987; Grant et al., 1988). Genetic and biochemical analysis of quinate non-utilizing mutants demonstrated that the qut genes map in a cluster and that two genes, qut $A$ and qut $\mathrm{R}$,

chelating (domain); quinate dehydrogenase, EC 1.1.1.24; QUTA, positively acting protein mediating the transcriptional regulation of the quinic acid utilization gene cluster of $\boldsymbol{A}$. nidulans; QUTR, negatively acting protein mediating the transcriptional regulation of the quinic acid utilization gene cluster of $A$. nidulans; SSCP, single-strand conformation polymorphism; TAD, transcription activation domain. 
are responsible for mediating the regulation of qut pathway enzyme production at the level of transcriptional control (Grant $e t$ al., 1988; Hawkins et al., 1988; Lamb et al., 1990, 1992). The qut $A$ gene was proposed to encode a positively acting regulatory protein, and subsequent sequence analysis of the cloned gene demonstrated (a) the presence of a putative zinc binuclear motif near the $\mathrm{N}$ terminus of the encoded QUTA protein; and (b) a region of high localized negative charge at the extreme Cterminus, which may possibly act as a transcription activation domain (TAD; Beri et al., 1987). Genetic analysis of mutations mapping in the qut $\mathrm{R}$ gene suggested that the encoded QUTR protein was a negatively acting regulatory protein. Subsequent sequence analysis of the cloned gene demonstrated that the encoded QUTR protein had no known motifs capable of facilitating DNA binding, leading to the proposal that the QUTR protein mediated its negative effect by directly binding to the QUTA protein (Hawkins et al., 1992, 1993a, b).

Comparative sequence analysis of the enzymes and proteins comprising the qut and shikimate pathways has revealed a complex web of evolutionary relationships. These relationships have been reviewed (Hawkins $e t$ al., 1993a), and in the context of this work the most remarkable proposal is that the QUTA and QUTR proteins are related to metabolic enzymes active in the shikimate pathway. On the basis of amino acid sequence alignments, the QUTA and QUTR proteins are proposed to be homologous with the five domains comprising the AROM protein (Anton et al., 1987; Charles et al., 1986; Hawkins, 1987; Hawkins et al., 1992, 1993b). The AROM protein catalyses the five consecutive steps converting 3deoxy-D-arabino-heptulosonate 7-phosphate to 5enolpyruvyl shikimate 3-phosphate in the shikimate pathway, with two of these steps common to the qut pathway (for a review see Hawkins et al., 1993a). The QUTA and QUTR proteins have therefore been proposed to have their origins in the splitting of a duplicated copy of the $\operatorname{arom} A$ gene or its precursor, with the QU'TA protein evolving at least in part by acquiring a zinc binuclear cluster motif to facilitate DNA binding (Hawkins et al., 1993b). It has been proposed that the enzymic activities of both proteins (QUTA and QUTR) have been lost, but that the QUTR protein has maintained its ability to recognize its former substrates, which now act as inducers of transcription by binding to the QUTR protein, disrupting its repressing function (Hawkins et al., 1992, 1993b; Bugg et al., 1991; Lamb et al., 1995).

The sequence similarity between the QUTA protein and the $\mathrm{N}$-terminal two domains of the AROM protein (DHQ synthase and EPSP synthase; see Fig. 1) is below $20 \%$, which is in the region where the possibility of fortuitous similarity is significant. The problems of discerning sequence similarity between highly diverged homologous sequences (i.e. those having a common ancestor) that have evolved new functions have been discussed recently (Hawkins et al., 1994; Hawkins \& Lamb, 1995; and references therein).

Amongst all quinate non-utilizing $(q u t)$ mutants analysed, the major proportion (48 of 149) proved non-inducible for all three enzymes that comprise the metabolic pathway due to mutations in the qut $A$ gene. Over half (29) of these mutants proved recessive, many (16) semi-dominant and a few (3) fully dominant in growth tests on quinic acid when combined in heterozygous diploid strains with a wild-type (qut $A^{+}$) strain (Grant et al., 1988). The dominance observed was interpreted to indicate that in these mutants, a form of the QUTA protein was produced that competed with the wild-type protein to fully block or diminish its function in promoting gene expression

In this communication we extend the analysis of domain structure and function within the QUTA protein and report experiments designed to probe the possible involvement of autoregulation of the qut $A$ gene.

\section{METHODS}

Plasmids, recombinant lambda and strains. The origins of the recombinant phage lambda and plasmids other than those constructed as part of the research reported here have been described previously (Hawkins et al., 1985; Beri et al., 1987, 1990; Moore \& Hawkins, 1993). The Escherichia coli and $A$. nidulans strains other than those constructed as part of this research have also been described previously, as have methods for their growth and propagation (Kinghorn \& Hawkins, 1982; Grant et al., 1988; Hawkins \& Smith, 1991; Lamb et al., 1992; Studier et al., 1990).

Materials. Chemicals and solvents other than dehydroquinate (DHQ) were of AnalaR or greater purity, and were purchased from local suppliers. DHQ was made from quinate and purified by chromatography as described by Grewe \& Haendler (1966). Quinate and NAD were from Sigma and dehydroshikimate was made enzymically from DHQ using either purified type I 3dehydroquinase from Salmonella typhi or type II 3dehydroquinase from Mycobacterium tuberculosis (Moore et al., 1992, 1993). General molecular biology reagents were from Pharmacia or Gibco BRL, Taq polymerase was from BCL, plasmids pGEX-2T, pKK233-2 and pTrc99a were from Pharmacia, and plasmid pRSETB was from Invitrogen. Activated Sepharose $4 \mathrm{~B}$ and chelating Sepharose FF were from Pharmacia; GSH-Sepharose $4 \mathrm{~B}$ was produced according to the manufacturer's instructions accompanying the plasmid pGEX2 T. Specific 30-mer oligonucleotides were purchased from the University of Newcastle upon Tyne Central Facility for Molecular Biology. A synthetic QUTA peptide, SNPKRQRVSRAC, was purchased from Biomac, Glasgow University, ${ }^{65} \mathrm{Zn}$ was from Amersham, and Dynabeads were from Dynal UK.

Methods. Restriction endonucleases were used according to the manufacturer's recommendations, and PCR amplification of target DNA sequences was as previously described (Van den Hombergh et al., 1992; Moore \& Hawkins, 1993). All other routine molecular biology protocols followed individual manufacturer's recommendations or were as previously described (Maniatis et al., 1982). Quinate dehydrogenase, 3-dehydroquinase and dehydroshikimate dehydratase assays were performed as previously described (Grant et al., 1988). Transformation of $A$. nidulans and the preparation of cell-free extracts from enzyme assay were as previously described (Lamb et al., 1991 ; Grant et al., 1988). An in vitro colour test, 'PCA spot test', was used to detect the presence of quinate pathway enzymes in young mycelium (Grant et al., 1988). Single-strand conformation polymorphism (SSCP) analysis of the qut $A$ mutant strains was carried out as described by Orita et al. (1989). [ $\alpha-$ $\left.{ }^{32} \mathrm{P}\right] \mathrm{dCTP}$ was used to label the DNA produced in the PCR prior 
to digestion with selected restriction endonucleases and subsequent separation of single- and double-stranded forms by electrophoresis in a non-denaturing polyacrylamide gel (Mackay et al., 1993). For DNA sequencing, double-stranded PCR products were electrophoresed through low-melting-point agarose and purified by the 'Gene Clean' procedure (TM Company) to ensure removal of unincorporated primers. DNA sequencing was done by standard methods (Sanger et al., 1977; Biggin et al., 1983). A. nidulans genomic DNA was isolated as previously described (Charles et al., 1986) and was used in the PCR preceding the SSCP analysis of DNA from wild-type and qut $A$ mutant strains.

Protocols for small- and large-scale growth and induction of fusion-protein synthesis in E. coli with IPTG were as previously described (Hawkins \& Smith, 1991; Moore \& Hawkins, 1993; Hawkins et al., 1993c). Purification of fusion proteins containing the GST domain of Schistosoma japonicum were as described by Hawkins et al. (1993c).

SDS-PAGE was carried out by the method of Laemmli (1970), and proteins immobilized by electrophoretic transfer to nitrocellulose using standard methods (Burnette, 1981; Samson, 1986). Rabbit antibodies were raised against a synthetic QUTA peptide, and used in Western blot analysis to detect QUTA proteins produced in E. coli by the method of Samson (1986). In vitro binding of zinc to proteins immobilized on nitrocellulose was determined as described by Barbosa et al. (1989). Total RNA was purified by the method of Cathala et al. (1983) and poly $\left(\mathrm{A}^{+}\right)$mRNA was prepared from total RNA using Dynabeads Oligo(dT) and following the manufacturer's protocol.

\section{RESULTS AND DISCUSSION}

\section{Mapping and sequence analysis of qutA mutations}

To gain further insight into the functional domains within the QUTA activator protein we wished to determine the

\section{Table 1. Genetic mapping of the qutA activator gene locus in A. nidulans}

The numbers in the table represent the frequency (per $10^{6}$ ascopores plated in selective medium) of quinic-acid-utilizing recombinants $\left(q u t^{+}\right)$in crosses between the qut $A$ mutants indicated. The arrows show on which side of the sign-post marker particular alleles are located, thereby defining the interval to which the mutation was allocated based upon the distribution of the qutR16 flanking marker. Numbers in parentheses indicate very close linkage where the mutation could not be ordered with confidence. The phenotypes of heterozygous diploid strains with the qut $A^{+}$wild-type allele in combination with each mutant allele are shown based upon growth on quinic acid plates: diploids with a dominant qut $A$ allele (D) produced no growth; recessive qut $A$ alleles $(\mathrm{R})$ full normal wild-type growth (identical with that of a qut $A^{+} /$qut $A^{+}$homozygote); semi-dominant qutA alleles (SD) a marked decrease in growth, both in the density of the mycelium and amount of conidiation, their growth appearing roughly $75 \%$ of that compared to wild-type $(100 \%)$ or the dominant mutants $(0 \%)$.

\begin{tabular}{|c|c|c|c|c|c|}
\hline \multirow{2}{*}{$\begin{array}{c}\mathrm{R} 153 \text { qutA } \\
\text { strain }\end{array}$} & \multirow[t]{2}{*}{ Phenotype } & \multicolumn{4}{|c|}{ R21 qutA $552 / 633 / 506 / 636$; qutR16 strain } \\
\hline & & $\begin{array}{c}\text { R153 qutA } \\
\times \\
552(\mathrm{r})\end{array}$ & $\begin{array}{c}\mathrm{R} 153 \text { qutA } \\
\times \\
633(\mathrm{r})\end{array}$ & $\begin{array}{c}\mathrm{R} 153 \text { qutA } \\
\times \\
506(\mathrm{r})\end{array}$ & $\begin{array}{c}\text { R153 qutA } \\
\times \\
636(\mathrm{r})\end{array}$ \\
\hline 380 & $\mathrm{R}$ & $417 \leftarrow 1$ & & $436 \leftarrow 1$ & \\
\hline 404 & SD & $133 \leftarrow 1$ & & $369 \leftarrow i$ & \\
\hline 402 & SD & $172 \leftarrow 1$ & & $242 \leftarrow 1$ & \\
\hline 422 & SD & $63 \leftarrow 1$ & & $232 \leftarrow 1$ & \\
\hline 423 & SD & $70 \leftarrow 1$ & & $458 \leftarrow 1$ & \\
\hline 400 & SD & $19 \leftarrow 1$ & & $174 \leftarrow 1$ & \\
\hline 394 & SD & (3) & $88 \leftarrow 1$ & $245 \leftarrow 1$ & $106 \leftarrow$ \\
\hline 341 & $\mathrm{SD}$ & $\mid \rightarrow 6$ & $84 \leftarrow 1$ & & $165 \leftarrow 1$ \\
\hline 393 & $\mathrm{R}$ & $\mid \rightarrow 10$ & $136 \leftarrow 1$ & $193 \leftarrow 1$ & $214 \leftarrow \mid$ \\
\hline 386 & $\mathrm{SD}$ & $\rightarrow 17$ & $34 \leftarrow 1$ & $151 \leftarrow 1$ & $55 \leftarrow$ \\
\hline 4 & SD & $\mid \rightarrow 23$ & $22 \leftarrow 1$ & $99 \leftarrow 1$ & $127 \leftarrow 1$ \\
\hline 384 & $\mathrm{SD}$ & $\rightarrow 28$ & $21 \leftarrow 1$ & $83 \leftarrow 1$ & $117 \leftarrow$ \\
\hline 399 & $\mathrm{R}$ & $\rightarrow 114$ & $11 \leftarrow$ & $47 \leftarrow 1$ & $64 \leftarrow 1$ \\
\hline 385 & $\mathrm{R}$ & $\rightarrow 104$ & $(0)$ & $41 \leftarrow 1$ & $10 \leftarrow 1$ \\
\hline 379 & $\mathrm{R}$ & $\rightarrow \rightarrow 141$ & (2) & $32 \leftarrow 1$ & $18 \leftarrow$ \\
\hline 324 & $\mathrm{R}$ & $\mid \rightarrow 371$ & $\mid \rightarrow 33$ & $(3$ & \\
\hline 361 & $\mathrm{R}$ & $\rightarrow 163$ & $\rightarrow 6$ & ) & $5 \leftarrow 1$ \\
\hline 389 & SD & & & $(2$ & $10 \leftarrow \mid$ \\
\hline 390 & $\mathrm{SD}$ & $\mid \rightarrow 868$ & $1 \rightarrow 20$ & ) & $7 \leftarrow 1$ \\
\hline 303 & $\mathrm{R}$ & $\rightarrow 168$ & $\rightarrow 66$ & & (1) \\
\hline 444 & $\mathrm{R}$ & $\rightarrow 218$ & $\rightarrow 39$ & $\mid \rightarrow 19$ & \\
\hline 382 & $\mathrm{D}$ & & $\mid \rightarrow 132$ & $\rightarrow 23$ & $\mid \rightarrow 17$ \\
\hline 214 & $\mathrm{D}$ & $\mid \rightarrow 286$ & $\mid \rightarrow 221$ & $\rightarrow 144$ & $\mid \rightarrow 38$ \\
\hline
\end{tabular}




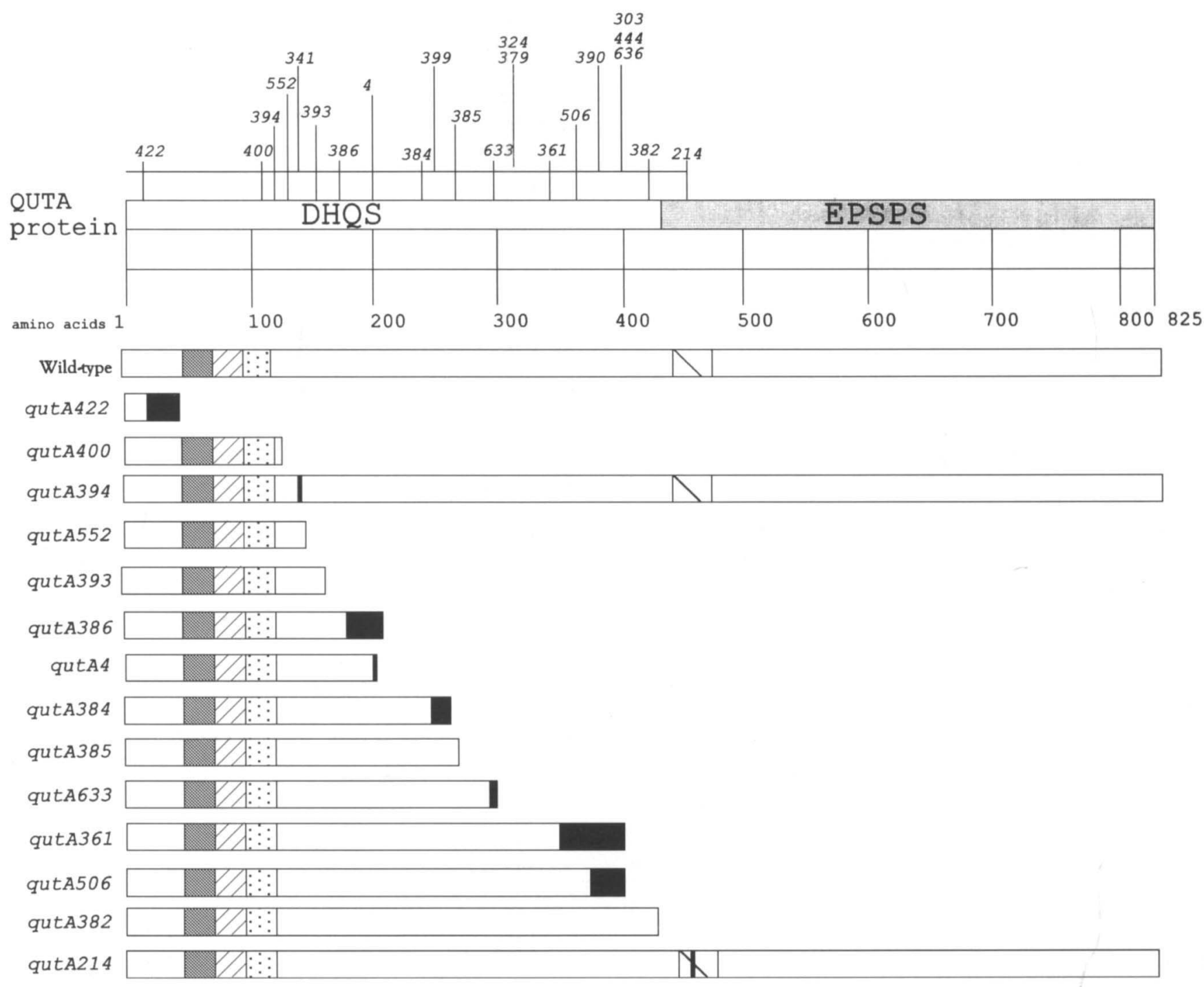

Fig. 1. Predicted proteins produced by translation of the qutA $A^{+}$gene and qutA mutants. DHQS, the region of the QUTA protein homologous with the AROM protein DHQ synthase domain; EPSP, the region of the QUTA protein homologous with the AROM protein EPSP synthase domain; 圈, zinc cluster domain (aa 49-76); 叉, linker region (aa 77-95); 0 , DNAdependent dimerization domain (aa 95-110); $\triangle$, TAD (aa 448-482); $\boldsymbol{\square}$, non-QUT amino acids incorporated following a frameshift mutation, or in the case of mutants 214 and 394, following a missense mutation.

nature and locations of the changes within representative classes (recessive, semi-dominant and dominant) of qut $A$ non-inducible mutant strains. To attempt to ensure that we determined the changes in mutants distributed throughout the qut $A$ gene, the relative positions of 23 qut $A$ mutations were determined by genetic analysis, which in turn might guide the choice of mutant strains for DNA sequence analysis.

Close linkage of the qut $\mathrm{R}$ repressor gene to qut $A(4 \%$ recombination) at the distal end of the qut gene cluster suggested the opportunity to extend the method used to map the qut gene cluster (Grant et al., 1988) in order to map mutations in the qut $A$ locus. In this method the qut genes were ordered by the distribution of a recessive constitutive mutation ( $q u t \mathrm{R} 16$ ) used as a flanking marker in three-point test crosses. This strategy requires the availability of some qut $A$ mutations coupled to qut $\mathrm{R} 16$ to serve as 'markers' within the qut $A$ locus. For this purpose, a further series of new qut mutants were isolated in the strain R21 qutR16 and classified by complementation analysis in heterozygous diploid strains in combination with known qut mutant strains. Four new qut $A$ mutants (qut $A 506,552,633$ and 636 ) were recovered on the basis of their functional identity with the wellcharacterized recessive mutant $\mathrm{R} 153$ qut $A 303$. All four new qut $A$ mutations proved to be recessive. Each of the double mutant strains (R21 qutR 16, qut $A 506$ or 552 or 


\section{Table 2. Frequency of recombination in the qutA locus}

The frequency of $q u t^{+}$recombinants in the crosses between qut $A$ mutant strains is shown in relation to the physical separation of the mutations. The value of the ratio ranged from 0.03 to 0.58 , the majority of values falling between 0.1 and 0.3 (26 of 31 ), with an overall mean of $0 \cdot 21$.

\begin{tabular}{|c|c|c|c|}
\hline $\begin{array}{l}\text { Genetic } \\
\text { interval }\end{array}$ & $\begin{array}{l}\quad 10^{6} \times \\
\text { Recombination } \\
\text { frequency (RF) }\end{array}$ & $\begin{array}{l}\text { Physical } \\
\text { distance } \\
\text { (bp) }\end{array}$ & $\begin{array}{l}\text { Ratio } \\
\text { RF/bp }\end{array}$ \\
\hline $402-552$ & 172 & 672 & $0 \cdot 26$ \\
\hline $422-552$ & 67 & 384 & $0 \cdot 17$ \\
\hline $400-552$ & 19 & 80 & $0 \cdot 24$ \\
\hline $394-522$ & 3 & 64 & 0.05 \\
\hline $552-393$ & 10 & 67 & $0 \cdot 15$ \\
\hline $552-386$ & 17 & 101 & $0 \cdot 17$ \\
\hline $552-4$ & 23 & 183 & $0 \cdot 13$ \\
\hline $552-384$ & 28 & 338 & 0.08 \\
\hline $552-385$ & 104 & 384 & $0 \cdot 27$ \\
\hline $552-361$ & 163 & 617 & $0 \cdot 26$ \\
\hline $552-214$ & 286 & 941 & $0 \cdot 30$ \\
\hline $394-633$ & 88 & 514 & $0 \cdot 17$ \\
\hline $393-633$ & 136 & 383 & 0.36 \\
\hline $386-633$ & 34 & 349 & $0 \cdot 10$ \\
\hline 4-633 & 22 & 267 & $0 \cdot 08$ \\
\hline $384-633$ & 21 & 112 & $0 \cdot 19$ \\
\hline $385-633$ & 0 & 66 & - \\
\hline $633-361$ & 6 & 167 & $0 \cdot 04$ \\
\hline $633-382$ & 132 & 432 & $0 \cdot 31$ \\
\hline $633-214$ & 221 & 488 & $0 \cdot 45$ \\
\hline $402-506$ & 242 & 1363 & $0 \cdot 18$ \\
\hline $422-506$ & 232 & 1075 & $0 \cdot 22$ \\
\hline $400-506$ & 174 & 771 & $0 \cdot 23$ \\
\hline $394-506$ & 245 & 755 & 0.32 \\
\hline $393-506$ & 193 & 624 & 0.31 \\
\hline $386-506$ & 151 & 590 & $0 \cdot 26$ \\
\hline $4-506$ & 99 & 508 & $0 \cdot 19$ \\
\hline $384-506$ & 83 & 353 & 0.24 \\
\hline $385-506$ & 41 & 307 & 0.13 \\
\hline $361-506$ & 2 & 74 & 0.03 \\
\hline $506-382$ & 23 & 194 & $0 \cdot 12$ \\
\hline $506-214$ & 144 & 250 & 0.58 \\
\hline
\end{tabular}

633 or 636 ) was crossed with a representative number of $\mathrm{R} 153$ qut $A$ mutants, and qut $A^{+}$recombinants isolated by plating ascopores pooled from 5-20 hybrid fruiting bodies in selective medium (minimal agar medium with quinic acid as sole carbon source). The mutant strains tested were genetically stable (reversion rates $<10^{-6}$ ), and the recombination frequencies observed fell in the range from not detectable $(0)$ to several hundred qut $A^{+}$progeny in $10^{6}$ ascopores plated. A number of the qut $A^{+}$ recombinants from each cross were classified for their constitutive phenotype using a rapid 'spot-test' for the ability of mycelium grown on a non-inducing carbon source (glycerol) to metabolize quinate to protocatechuate, trapped in a colorimetric reaction (Grant $e t a l$., 1988). The resultant matrix (Table 1) reliably mapped mutations to intervals between the 'sign-post' markers, which fortunately proved reasonably well separated, and resolved the majority of mutants examined (Fig. 1). As expected, recombination frequencies were not additive, but the genetic data proved invaluable in the selection of mutant strains for DNA sequence analysis.

Molecular analysis was initiated by the use of SSCP (Orita et al., 1989; Mackay et al., 1993) to locate mutations to defined restriction fragments in the qut $A$ gene. Four mutations (qut A422, 400, 552 and 500) were physically mapped by this method and served to align the genetic and physical maps unambiguously. On this basis 14 qut $A$ mutations were chosen for DNA sequence analysis (Fig. 1), and in each case the mutation identified by SSCP analysis was confirmed by sequence determination using a newly prepared PCR template. The relationship of recombination frequency and the physical separation of the mutations for each genetically mapped interval is shown in Table 2. There was no obvious bias in recombination across the locus and overall qut ${ }^{+}$recombinants were recovered at a frequency of 1 in $10^{6}$ for each 56 bp interval.

The positions and nature of the mutant changes are summarized in Fig. 1 and Table 3, inspection of which leads to the following conclusions: (a) the genetic and physical maps are precisely co-linear; (b) none of the mutations are located within the putative zinc binuclear cluster motif; (c) only two of the 14 mutants sequenced were missense mutants (qut A394, 214); and perhaps most strikingly (d) all 14 mutations are confined to the $\mathrm{N}$ terminal $55 \%$ of the protein, with 13 mutations located within the DHQ-synthase-like domain and only one mutation (qut A214) located within the EPSP-synthaselike domain.

The missense dominant mutant qut $A 214$ is of particular interest as it specifies a full-length QUTA protein containing the previously identified putative transcription activation domain (TAD) at the extreme C-terminus of the EPSP-synthase-like domain (Beri et al., 1987). This mutant has a dominant phenotype, which strongly implies that the encoded protein is stable and able to fold into a configuration that allows efficient DNA binding, thus out-competing the wild-type QUTA protein, but has no functional TAD. Mutant qut $A 214$ is an $\mathrm{E} \rightarrow \mathrm{K}$ change in a region of localized high negative charge, 8 acidic residues in a sequence of 29 amino acids, which is $27.5 \%$ compared to an average value of $10.7 \%$ for the complete QUTA protein. Although it has been shown recently (Van Hoy et al., 1993; Leuther et al., 1993), that TADs do not necessarily have an acidic nature, mutant qut $A 214$ may however define a TAD in the QUTA protein. We note that in the same region in the equivalent $\mathrm{QA}-1 \mathrm{~F}$ protein of Neurospora crassa the $E$ residue is conserved and is also part of a sequence that has $27.5 \%$ acidic residues (Geever et al., 1989), supporting the view that this concentration of negative charge is not fortuitous. The $\mathrm{E}$ $\rightarrow \mathrm{K}$ change at QUTA amino acid 457 therefore either destabilizes the activity of a spatially distinct TAD, or we believe more likely identifies an in vivo functionally active 


\section{Table 3. Positions and nature of the qutA mutations}

DNA from wild-type $A$. nidulans and the qut $A$ mutants shown was subjected to SSCP analysis to approximately locate the positions of the mutations. The nucleotide sequence changes were then determined by directly sequencing the PCR-amplified DNA using the dideoxy chain-termination method.

\begin{tabular}{|cccccc|}
\hline Mutant & Phenotype* & $\begin{array}{c}\text { Base } \\
\text { alteration } \dagger\end{array}$ & $\begin{array}{c}\text { Base } \\
\text { number }\end{array}$ & $\begin{array}{c}\text { AA } \\
\text { alteration } \ddagger\end{array}$ & $\begin{array}{c}\text { Stop } \\
\text { number } \$\end{array}$ \\
\hline 422 & $\mathrm{SD}$ & $+\mathrm{A}$ & 44 & $15 \mathrm{wt}+23$ & 39 \\
400 & $\mathrm{SD}$ & $-\mathrm{A}$ & 348 & $116 \mathrm{wt}+1$ & 117 \\
394 & $\mathrm{SD}$ & $\mathrm{A} \rightarrow \mathrm{G}$ & 364 & $122 \mathrm{I} \rightarrow \mathrm{T}$ & 825 \\
552 & $\mathrm{R}$ & $\mathrm{G} \rightarrow \mathrm{A}$ & 428 & $142 \mathrm{wt}$ & 143 \\
393 & $\mathrm{R}$ & $\mathrm{G} \rightarrow \mathrm{A}$ & 495 & $164 \mathrm{wt}$ & 165 \\
386 & $\mathrm{SD}$ & $-\mathrm{C}$ & 529 & $177 \mathrm{wt}+30$ & 208 \\
4 & $\mathrm{SD}$ & $-\mathrm{A}$ & 611 & $205 \mathrm{wt}+2$ & 208 \\
384 & $\mathrm{SD}$ & $+\mathrm{C}$ & 766 & $255 \mathrm{wt}+11$ & 267 \\
385 & $\mathrm{R}$ & $\mathrm{T} \rightarrow \mathrm{G}$ & 812 & $270 \mathrm{wt}$ & 271 \\
633 & $\mathrm{R}$ & $+\mathrm{T}$ & 878 & $292 \mathrm{wt}+7$ & 300 \\
361 & $\mathrm{R}$ & $+\mathrm{A}$ & 1045 & $348 \mathrm{wt}+48$ & 397 \\
506 & $\mathrm{R}$ & $+\mathrm{G}$ & 1119 & $373 \mathrm{wt}+23$ & 397 \\
382 & $\mathrm{D}$ & $\mathrm{T} \rightarrow \mathrm{A}$ & 1313 & $437 \mathrm{wt}$ & 438 \\
214 & $\mathrm{D}$ & $\mathrm{G} \rightarrow \mathrm{A}$ & 1369 & $457 \mathrm{E} \rightarrow \mathrm{K}$ & 825 \\
\hline
\end{tabular}

$* \mathrm{R}, \mathrm{SD}$ and $\mathrm{D}$ indicate a phenotype of recessive, semi-dominant or dominant for each allele when combined in a diploid with a wild-type qut $A^{+}$allele.

† Arrows between two bases show either transversions or transitions and the designation + A, C, G or T signifies the addition of this base, whereas - A or C indicates the loss of this base.

¥'AA alteration' indicates the change induced in the amino acid sequence by each of the mutants studied. 'wt' shows the number of wild-type amino acids produced before either a translational stop is produced or a frameshift occurs. In the latter case the symbol ' + ' followed by a number indicates the number of adventitious amino acids produced out of frame before a randomly generated stop codon is encountered. In mutants qut $A 394$ and 214 the nature of the missense mutation is shown in the single-letter amino acid code.

'Stop number' refers to the number of amino acids encoded by a particular allele before a translational stop is encountered.

TAD in the extreme N-terminus of the EPSP-synthaselike domain in the QUTA protein. We note that the position of this TAD places it immediately adjacent to a proposed linker region between the QUTA DHQsynthase-like and EPSP-synthase-like domains and that this region may have some flexibility.

All of the recessive qut $A$ mutants are nonsense or frameshift mutations producing QUTA proteins containing the putative zinc binuclear cluster motif and the specificity region, but truncated within the limits of the DHQ-synthase-like domain. The probable molecular basis for their recessive phenotype is that the truncated QUTA proteins either are unstable and are proteolytically degraded in vivo or simply are unable to produce a folded protein with biological activity.

The existence of the dominant and semi-dominant classes of qut $A$ mutant strongly implies that in these mutants a stable form of the QUTA protein is produced that is able to fold and either compete with the wild-type QUTA protein for the binding sites within qut gene promoters or interact directly with wild-type QUTA protein to produce inactive heterodimers.
The mutation in qut $A 382$ introduces a translational stop codon two amino acids away from the end of the DHQsynthase-like domain, defined by alignment with the $A$. nidulans pentafunctional AROM protein (Hawkins et al., 1993b). We interpret the dominant phenotype of mutant qut $A 382$ to indicate that this strain is producing a stable, soluble but truncated QUTA protein that corresponds only to the DHQ-synthase-like domain. We have recently shown that the DHQ synthase domain of the AROM protein is completely stable and retains efficient enzyme activity when isolated from the rest of the pentafunctional enzyme (Moore et al., 1994). This observation strengthens the following interpretation for the molecular basis of the qut $A 382$ mutant phenotype. The DHQ-synthase-like domain of the QUTA protein contains a putative zinc binuclear cluster motif; therefore the simplest interpretation of the dominant non-inducible phenotype is that this domain when isolated in the truncated protein can bind to the target qut gene promoters but lacks a transcription activation domain. Binding of this DHQ-synthase-like domain of QUTA will therefore 'mop up' the specific binding sites, and in a heterozygous diploid with the wildtype qut $A$ gene will out-compete the wild-type QUTA 
protein for these sites, thus producing the dominant phenotype. It is also possible however that the effect of the qut $A 382$ mutation may be caused by heterodimer formation of the encoded truncated QUTA protein with the endogenous wild-type QUTA protein.

The semi-dominant frameshift mutant qut $A 422$ is of special interest as it is predicted to produce a truncated QUTA protein 38 amino acids long. The first 15 amino acids are the same as wild-type; however the insertion of an $\mathrm{A}$ base at nucleotide 44 alters the reading frame to include a further 23 heterologous amino acids before a stop codon occurs. This region of the QUTA protein contains no recognized functional motifs, and yet the semidominant phenotype displayed by mutant qut $A 422$ implies that the truncated QUTA protein that it encodes is having some physiological effect. In the absence of any other recognized motif we speculate that the first 15 amino acids of the QUTA protein encode at least part of a nuclear localization signal. It is possible that the extra 23 heterologous amino acids associated with the truncated QUTA protein (caused by translating part of the qut $A$ gene out of frame) specified by mutant qut $A 422$ are responsible for this proposed function, but we feel it is most likely that the semi-dominant phenotype of qut $A 422$ is a consequence of the first 15 amino acids. The other semi-dominant mutants containing the putative zinc binuclear cluster motif (but lacking the EPSP-synthaselike domain), and the specificity region may have their phenotypic effect either by competitive DNA binding, by heterodimer formation diluting out a pool of transcriptionally active wild-type dimers, or both. Taken together these data provide strong support for the bidomain model for the structure of the QUTA protein and suggest the presence of a novel TAD located adjacent to a hinge region connecting the two domains.

\section{Transcription from qutA is autoregulated}

The QUTA protein is responsible for directing the transcription of the genes comprising the qut gene cluster and has also been shown to direct the transcription of heterologous genes fused to the qutE promoter (Grant $e t$ al., 1988; Lamb et al., 1991; Moore et al., 1992).

To investigate the pattern and possible regulation of transcription of the qut $A$ gene, a series of qualitative and quantitative experiments were performed. Poly $\left(\mathrm{A}^{+}\right)$ mRNA from quinate induced and non-induced cultures of $A$. nidulans strains $\mathrm{R} 153$ (wild-type), qutR16 (constitutive mutant) and qut $A 303$ (non-inducible mutant) was isolated and subjected to Northern blot analysis with radiolabelled qut $A, q u t \mathrm{R}, q u t B$ and $q u t G \mathrm{DNA}$. The results are shown in Fig. 2(a).

Northern blot analysis has not been reported for the qut $A$, $q u t R$, qut $G$ or $q u t B$ genes; therefore the presence of a quinate-inducible mRNA for each gene was determined. The quinate-inducible mRNA specific to the qut $A$, qut $\mathrm{R}$ and $q u t G$ genes is shown in lanes 1-6 of Fig. 2(a); the mRNA for $q u t B$ was also quinate-inducible (unpublished data). The presence of constitutively produced qut $A, q u t \mathrm{R}$ and $q u t B$ (as a representative example of one of the genes encoding an enzyme) mRNA in the constitutive mutant $q u t \mathrm{R} 16$ is shown in lanes 7, 8 and $11-14$ respectively. The absence of qut $A$-specific mRNA in the non inducible mutant qut $A 303$ is shown in lanes 9 and 10. The qut $A 303$ mutation is recessive and maps in the sequence encoding the N-terminal DHQ-synthase-like domain of the QUTA protein (see Fig. 1). Taken together with previous genetic experiments (Grant $e$ t al., 1988) these observations of the pattern of mRNA expression (Fig. 2a) strongly support the view that the QUTA protein is responsible for controlling transcription of the qut gene cluster in response to the presence of quinate, and that the QUTA protein autoregulates the expression of the qut $A$ gene which encodes it.

In order to follow the kinetics of induction of qut-specific $\mathrm{mRNA}$ and enzymes, the levels of qut $A$, qutR and qutB mRNA and the activity of the qut $B$-encoded quinate dehydrogenase were determined at stages over a $3 \mathrm{~h}$ period following the quinate induction of a glucosegrown culture of wild-type R153. The results of this experiment are shown in Fig. 2(b), analysis of which leads to the following observations: (1) the appearance of qut $A$, $q u t R$ and $q u t B$ mRNA is concomitant and detectable after $15 \mathrm{~min}$, reaching apparent steady-state levels by $90 \mathrm{~min}$; (2) quinate dehydrogenase activity is detectable $60 \mathrm{~min}$ after the addition of quinate and rises approximately linearly for the following $2 \mathrm{~h}$. Taken as a whole, these data lend strong support to the hypothesis that the qut $A$ gene of $A$. nidulans is autoregulated.

\section{Truncated N-terminal peptides from the QUTA protein containing the putative zinc binuclear cluster motif are able to bind zinc in vitro}

The finding that none of the 13 mutations located within the QUTA DHQ-synthase-like domain were located within the putative zinc binuclear cluster motif is surprising and questions if this motif can bind zinc. Specific 30-mer oligonucleotides were used to PCR amplify the DNA sequence of qut $A$ from nt 1 to 387, which incorporates the putative zinc binuclear cluster motif. Following restriction endonuclease digestion, the amplified DNA was subcloned into the E. coli expression vectors pKK233-2, pTrc99a, pGEX-2T, pETGEXCT and $\mathrm{pRSETB}$. The first two vectors give the potential to produce non-fusion proteins (molecular mass $14 \cdot 15 \mathrm{kDa}$ ). The vectors $\mathrm{pGEX}-2 \mathrm{~T}$ and $\mathrm{pRSETB}$ give the potential to produce fusion proteins with either the glutathione $S$ transferase (GST) (fusion protein molecular mass $41.15 \mathrm{kDa}$ ) protein of Schistosoma japonicum or a metalchelating (MC) domain (fusion protein molecular mass $18.65 \mathrm{kDa}$ ) fused to the $\mathrm{N}$-terminal end of the experimental target protein. The plasmid pETGEXCT allows the production of fusion proteins with the GST domain fused to the C-terminus of the experimental target protein (Sharrocks, 1994). Recombinant plasmids were initially identified by colony hybridization using $\left[\alpha^{32} \mathrm{P}\right] \mathrm{dCTP}$ labelled PCR-amplified DNA and their correct construction verified by restriction endonuclease digestion. The 
(a)
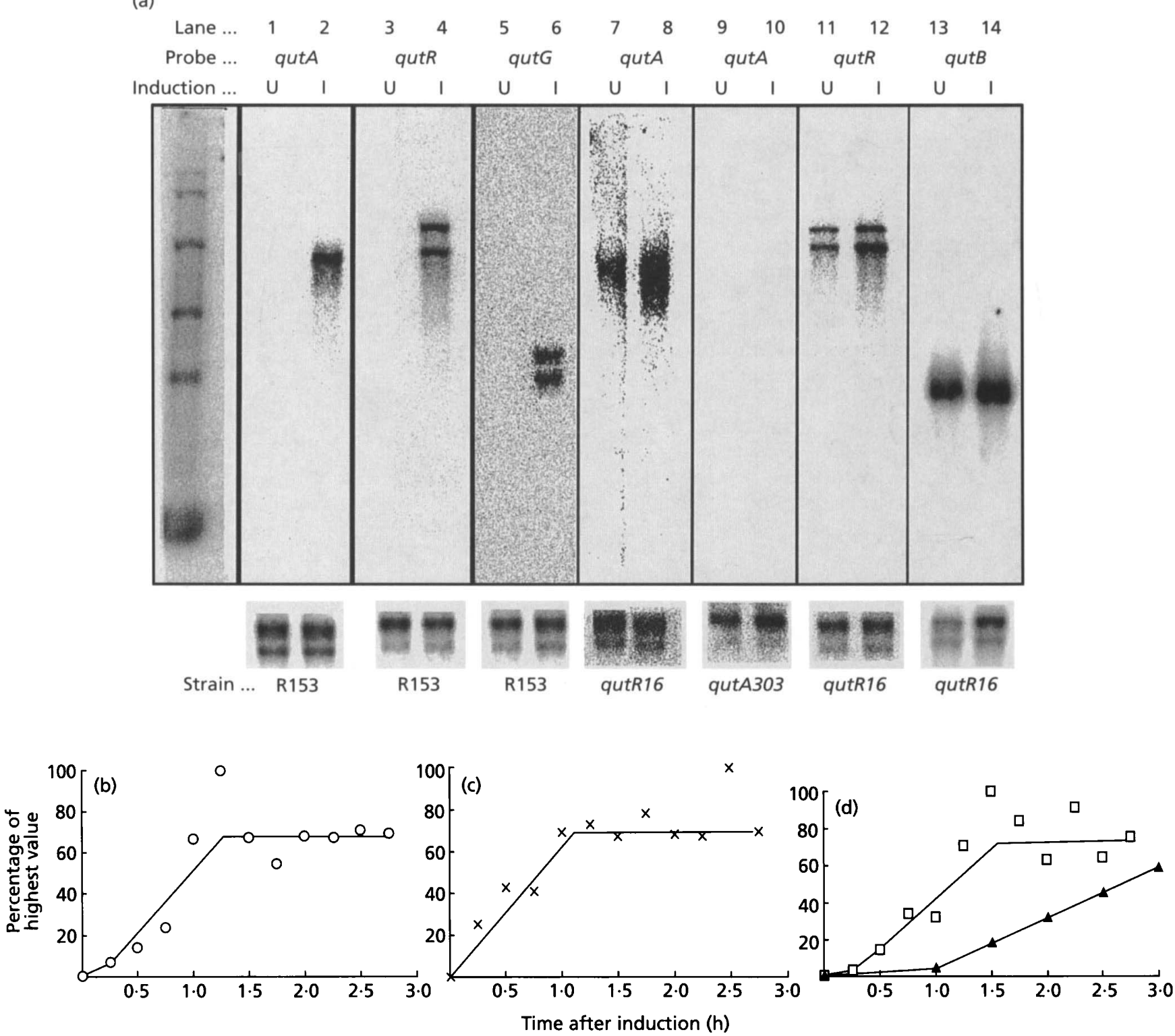

Fig. 2. Transcription studies. (a) Poly( $\left.A^{+}\right)$mRNA (1.5 $\mu \mathrm{g}$ per track) from quinate-induced (I) and uninduced (U) cultures of strains R153 (wild-type), qutR16 and qutA303 was subjected to denaturing agarose gel electrophoresis and transferred to nitrocellulose. The nitrocellulose sheets were then probed with PCR-amplified DNA fragments specifying either the entire coding region of the qutA gene, the qutR gene, the qutB gene or the qutG gene and subsequently labelled with $[\alpha-$ $\left.{ }^{32} \mathrm{P}\right] \mathrm{dCTP}$ by nick translation. In all cases an $\left[\alpha{ }^{32} \mathrm{P}\right] \mathrm{dCTP}$-labelled $0.83 \mathrm{~kb} \mathrm{Ncol}-K$ pnl fragment from the $A$. nidulans actA gene was used as a probe to check equal loading and even transfer of mRNA species in all 14 lanes; the actin-specific mRNA is shown below the boxed qut-specific mRNA. The unlabelled track contains RNA size markers consisting of 0.24 , $1.4,2.4,4.4,7.5$ and $9.5 \mathrm{~kb}$, and is included as a representative example. Panel (a) is a composite of three separate gels; the data were collected by quantitative phosphoimaging. Probed filters were exposed for between $2 \mathrm{~h}$ (enzyme structural genes) and $48 \mathrm{~h}$ (regulatory genes). (b-d) Poly $\left(\mathrm{A}^{+}\right)$mRNA was extracted from replicate cultures of $A$. nidulans strain R153 (wild-type) that had been grown with glucose as carbon source and subsequently induced with $0.1 \%$ quinate. Extractions of total and poly $\left(\mathrm{A}^{+}\right)$mRNA were made from the replicate cultures harvested at intervals over a $3 \mathrm{~h}$ period. The poly $\left(\mathrm{A}^{+}\right)$mRNA was then sequentially probed for the presence of the qutA-, qutR-and actA-specific mRNA and a replicate filter of total RNA probed for the presence of qutB-specific mRNA as described in (a). In order to follow the kinetics of induction, phosphoimaging was used to quantify the levels of all four mRNA species at each of the time points and cell-free in vitro enzyme assays were used to measure the quinate dehydrogenase activity. Following the subtraction of an average background reading, the ratios of the qutA-, qutR-and qutB-specific mRNA relative to the actA-specific mRNA (which was used as an internal constitutive control) were determined. The graphs show the appearance of (b) qutA-specific mRNA (c) qutR-specific mRNA, and (d) qutB-specific mRNA ( $\square$ ) and quinate dehydrogenase ( $\boldsymbol{A}$ ). To allow the use of a single scale, in each case the highest value of the ratio with respect to the internal control actA mRNA was taken as $100 \%$. The values for the qutB-encoded quinate dehydrogenase are shown relative to the value (taken as $100 \%$ ) found in a replicate culture induced by the presence of quinate for $4 \mathrm{~h}$; it was known from previous data that qut pathway enzyme levels reached a maximum value $4-5 \mathrm{~h}$ after the addition of quinate. The graphs in (b-d) are therefore directly comparable. 


\section{Table 4. Plasmids used for expression studies}

Desired target DNA sequences were amplified by PCR using specific 30-mer oligonucleotides incorporating $5^{\prime}$ and $3^{\prime}$ Bam HI and EcoRI sites, respectively, for subcloning into the vector pGEX-2T. For subcloning into the vectors pKK233-2, pTrc99a, pETGEXCT and pRSETB, the PCR primers contained $5^{\prime}$ and $3^{\prime}$ sites for BspHI and HindIII, respectively. For subcloning into pETGEXCT, the PCR product was generated by oligonucleotides introducing $5^{\prime}$ and $3^{\prime} B s p \mathrm{HI}$ and HindIII sites respectively and was digested with BspHI and $N_{c o I}$ (there is a naturally occurring NcoI site immediately preceding the HindIII site artifically introduced on the $3^{\prime}$ PCR primer) and subcloned into NcoI-cut pETGEXCT. All the qut $A$-derived sequences specified the N-terminal 129 QUTA amino acids. Recombinant plasmids were rescued from ligation mixtures by transforming E. coli SK3430 and selection on complete medium containing $50 \mu \mathrm{g}$ ampicillin $\mathrm{ml}^{-1}$. The correct construction of individual plasmids was directly verified by restriction endonuclease digestion of purified plasmid preparations. NA, Not applicable.

\begin{tabular}{|lccccc|}
\hline $\begin{array}{l}\text { Expression } \\
\text { plasmid }\end{array}$ & Promoter & $\begin{array}{c}\text { Recombinant } \\
\text { plasmid designation }\end{array}$ & $\begin{array}{c}\text { Potential to } \\
\text { produce native } \\
\text { (N) or fusion (F) } \\
\text { proteins }\end{array}$ & $\begin{array}{c}\text { Fusion } \\
\text { domain }\end{array}$ & $\begin{array}{c}\text { Zinc domain production when } \\
\text { containing the 5' 387 bp qut A } \\
\text { sequence? }\end{array}$ \\
\hline pKK233-2 & $t r c$ & NA & N & NA & No \\
pTrc99a & $t r c$ & NA & N & NA & No \\
pGEX-2T & $t r c$ & pXF32-35 & F & GST & Yes, but degraded \\
pRSETB & T7 & pRF2 & F & GST & Yes, not degraded \\
pETGEXCT & $T 7$ & pCF1 & F & & \\
\hline
\end{tabular}

plasmids generated are summarized in Table 4. A 12-mer peptide corresponding to QUTA amino acid co-ordinates 38-49 inclusive was used to raise rabbit antibodies to the $\mathrm{N}$-terminal domain of the QUTA protein, and these were subsequently used as a means of identifying heterologous protein production in E. coli by Western blotting. The Cterminal Cys residue of this peptide corresponds to the first of the six Cys residues that comprise the putative zinc binuclear cluster (Beri et al., 1987). The antibodies produced were able to recognize and bind to the correct size zinc domain fusion protein and various degradation products of it (see Fig. 3a). The rabbit antibodies were used to screen $E$. coli lysates containing recombinant plasmids derived from pKK233-2, pTrc99a, pGEX-2T and pRSETB after fractionation by SDS-PAGE and Western blotting. Only recombinant plasmids (designated pXF32-35) derived from pGEX-2T were able to direct the production of protein that was specifically recognized by the anti-QUTA antibody; all the other recombinant plasmids based on the commercially available constructs failed to produce qut $A$-specified protein. The fusion protein produced by the pGEX-2T recombinant plasmids was heterogeneous, reproducibly yielding specific degradation products of the expected full-length GST fusion protein (see Fig. 3a). Recombinant plasmids were screened for their ability to specify stable fusions of the expected size by transformation into $\operatorname{rec} A$ (recombination deficient) and lon (protease deficient) strains of E. coli, but the same pattern of degradation was seen in each case (see Fig. 3a). The purpose of using these strains was to minimize the effects of DNA rearrangements or protease attack, which were considered as plausible explanations for the instability of the GST-QUTA fusion protein.

Recombinant plasmids derived from pETGEXCT, designated $\mathrm{pCF}$, were screened in E. coli for their ability to direct the production of a stable QUTA-GST fusion protein. Independently isolated, multiple examples of these recombinant plasmids were able to direct production of a QUTA-GST fusion protein of approximately the predicted molecular mass $(41.15 \mathrm{kDa})$. The fusion protein migrated slightly faster than expected during SDSPAGE; however, similar anomalous migration patterns with other proteins have been reported (Samson, 1986). When screened with anti-QUTA rabbit antibody, the fusion protein in strains containing pCF1 cross-reacted strongly, confirming that the protein was the desired QUTA-GST fusion (see Fig. 3d). The C-terminal fusion protein was soluble following sonication; however it was unable to bind to glutathione-substituted Sepharose 4B. To assess whether the QUTA-GST fusion protein could bind zinc in vitro, lysates of $E$. coli overproducing the QUTA-GST fusion protein specified by pCF1 (experimental), the GST domain alone (negative control), or a protein consisting of the qut $B$-encoded quinate dehydrogenase (Hawkins et al., 1993c) fused to the MC domain encoded by pRSETB (positive control) were serially diluted, and the proteins were separated by SDS-PAGE and screened with ${ }^{65} \mathrm{Zn}$ following Western blotting. The quinate dehydrogenase fusion protein (specified by recombinant plasmid $\mathrm{pRF} 2$ ), acted as a positive zinc-binding control, as the $4.47 \mathrm{kDa} \mathrm{MC}$ domain attached to its $\mathrm{N}$ terminus contains six histidine residues that are able to bind zinc atoms, facilitating purification by immobilized metal affinity chromatography. As shown in Fig. 3(b, c), both the experimental and the positive control proteins specifically bound zinc in vitro. Zinc binding was still seen in both these protein preparations when they were serially diluted 25 -fold lower than the concentration shown in Fig. 3 (data not shown).

These data support the interpretation, but do not unequivocally prove, that it is the putative zinc binuclear cluster motif in the fusion proteins that is specifically binding zinc. However, further analysis of the degraded polypeptides produced in E. coli strains containing the 
(a)
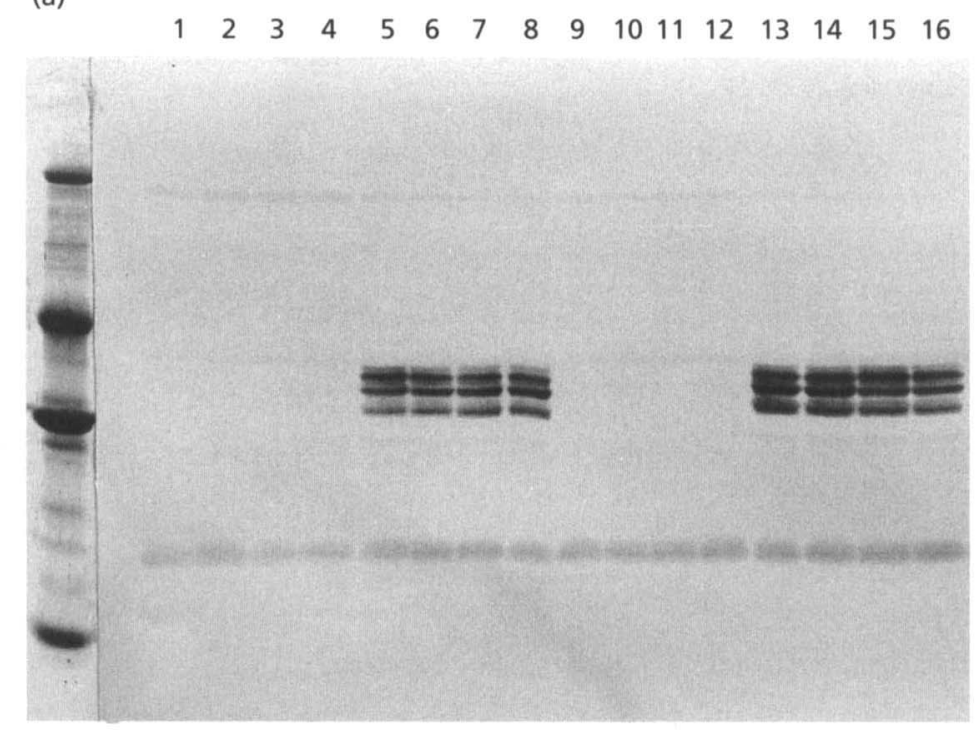

(b)

(c)

(d)
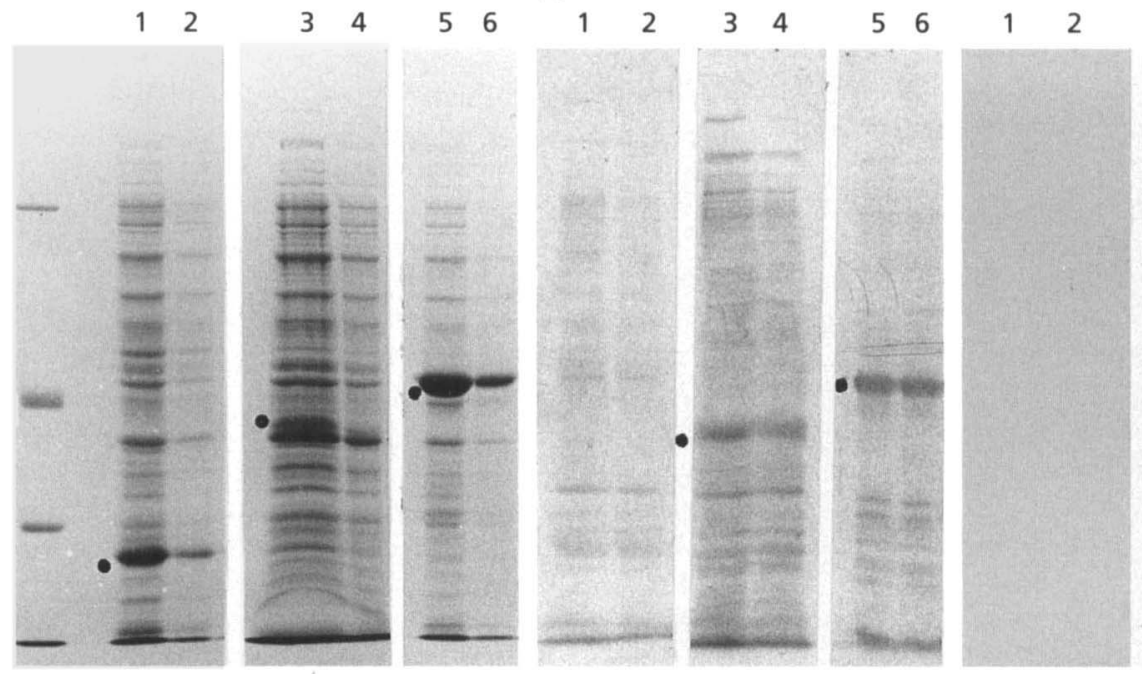

34

5

6

Fig. 3. (a) Detection of the QUTA-GST fusion protein and its breakdown products by in vitro antibody binding. Solubilized whole-cell extracts of IPTG-induced and uninduced $E$. coli strains containing recombinant pGEX2T (designated pXF) plasmids specifying the $\mathrm{N}$-terminal 129 amino acids of the QUTA protein were prepared, fractionated by SDS-PAGE, and proteins transferred to nitrocellulose. Equivalent numbers of cells were used in each track. Molecular mass standards [phosphorylase $b(91 \mathrm{kDa})$, alcohol dehydrogenase $(41 \mathrm{kDa})$; carbonic anhydrase $(29 \mathrm{kDa})$ and cytochrome $c$ $(12.8 \mathrm{kDa})]$ were co-electrophoresed in the un-numbered lane. The nitrocellulose-bound proteins were reacted with antiQUTA peptide antibody used at a dilution of 1 in 50 (Samson, 1986). (a) Tracks 1-4, E. coli BL21 containing plasmids pXF32-35, uninduced; tracks 5-8, E. coli BL21 containing plasmids pXF32-35, induced with IPTG; tracks 9-12, E. coli SK3430 containing plasmids pXF32-35, uninduced; tracks 13-16, E. coli SK3430 containing plasmids pXF32-35, induced with IPTG. $E$. coli BL21 is a protease-deficient recA $A^{+}$strain B (Studier et al., 1990), and SK3430 is a recA+ K12 strain with the normal complement of proteases. GLW55, a recA K12 E. coli strain (Hawkins \& Smith, 1991), gave identical results to those shown in (a) when harbouring the pXF plasmids. (b-d) Identification of the QUTA-GST fusion protein and zinc binding. Equivalent amounts of the GST specified by PGEX-2T (lanes 1 and 2), the QUTA-GST C-terminal fusion protein specified by PCF1 (lanes 3 and 4) and the MC domain-quinate dehydrogenase $\mathrm{N}$-terminal fusion protein specified by pRF2 (lanes 5 and 6), prepared as total protein extracts from IPTG-induced $E$. coli cells, were subjected to SDS-PAGE in three separate replicate gels. The three proteins of interest are marked by black dots. Following electrophoresis, gels were either stained with Coomassie blue (b) or electroblotted to nitrocellulose in the presence (c) or absence (d) of $0.025 \%$ SDS in the transfer buffer. The nitrocellulose filter in (c) was reacted with $50 \mu \mathrm{Ci}(1.85 \mathrm{MBq})^{65} \mathrm{ZnCl}_{2}$ and the filter in (d) was reacted with rabbit anti-QUTA peptide antibody. Molecular mass markers (as in a) were electrophoresed in each gel (shown only in b: un-numbered lane). Following SDS electroblotting the nitrocellulose sheet shown in (c) was incubated in renaturing buffer $(100 \mathrm{mM}$ Tris, $50 \mathrm{mM} \mathrm{NaCl}, 10 \mathrm{mM} \mathrm{DTT}, \mathrm{pH} \mathrm{6.8)}$ for $1 \mathrm{~h}$ with three changes of buffer prior to incubation with $50 \mu \mathrm{Ci}^{65} \mathrm{ZnCl}_{2}$ in $50 \mathrm{ml}$ labelling buffer $(100 \mathrm{mM}$ Tris, $50 \mathrm{mM} \mathrm{NaCl}, \mathrm{pH} 6.8)$. After washing for $1 \mathrm{~h}$ with three changes of wash buffer ( $100 \mathrm{mM}$ Tris, $50 \mathrm{mM} \mathrm{NaCl}, 1 \mathrm{mM} \mathrm{DTT}, \mathrm{pH} 6.8)$ the sheet was dried and autoradiographed (Barbosa et al., 1986). The non-SDS electroblotted nitrocellulose sheet (d) was blocked by overnight incubation in $1 \%$ 
GST-QUTA fusion proteins lends support to this interpretation. The degraded products were purified by affinity chromatography on glutathione-substituted Sepharose 4B, demonstrating that the GST domain was intact and that degradation was taking place at the $\mathrm{C}$ terminal end of the protein within the QUTA sequence. Western blot analysis showed that the higher molecular mass protein bands, that is those least degraded, were both recognized by the antibody to the QUTA peptide and that only these proteins were able to bind zinc (data not shown). Measurement of the molecular masses of the degraded proteins supports the conclusion that the lower molecular mass degraded proteins must have lost all or part of the putative zinc binuclear cluster motif and that this is correlated with the loss of ability to bind zinc.

\section{ACKNOWLEDGEMENTS}

This research was supported by UK Research Council funding. We thank Kirupa Sathasivam for her contribution to the genetic mapping, and Susan Lee for typing the manuscript.

\section{REFERENCES}

Anton, I. A., Duncan, K. \& Coggins, J. R. (1987). A eukaryotic repressor protein, the qa-IS gene product of Neurospora crassa, is homologous to part of the AROM multifunctional enzyme. $J$ Mol Biol 197, 367-371.

Barbosa, M. S., Lowry, D. R. \& Schiller, J. T. (1989). Papilloma virus polypeptides E6 and E7 are zinc-binding proteins. J Virol 63, 1404-1407.

Beri, R. K., Whittington, H., Roberts, C. F. \& Hawkins, A. R. (1987). Isolation and characterisation of the positively acting regulatory gene QUTA from Aspergillus nidulans. Nucleic Acids Res 15, 7991-8001.

Beri, R. K., Grant, S., Roberts, C. F., Smith, M. \& Hawkins, A. R. (1990). Selective overexpression of the QUTE gene encoding catabolic 3-dehydroquinase in multicopy transformants of Aspergillus nidulans. Biochem J 265, 337-342.

Biggin, M. D., Gibson, T. S. \& Hong, C. F. (1983). Buffer gradient gels and ${ }^{35} \mathrm{~S}$ label as an aid to rapid DNA sequence determination. Proc Natl Acad Sci USA 86, 3963-3965.

Bugg, T. D. H., Alefounder, P. R. \& Abell, C. (1991). An amino acid sequence motif observed amongst enzymes of the shikimate pathway. Biochem J 276, 841-843.

Burnette, N. W. (1981). 'Western blotting': electrophoretic transfer of proteins from sodium dodecyl sulphate polyacrylamide gels to unmodified nitrocellulose and radiographic detection with antibody and radioiodinated protein A. Anal Biochem 112, 195-203.

Cathala, G., Savouret, J. F., Mendez, B., West, B. L., Karin, B., Martial, J. A. \& Baxter, J. D. (1983). A method for isolation of intact translationally active ribonucleic acid. DNA 2, 329-335.

Charles, I. G., Keyte, J. W., Brammar, W. J., Smith, M. \& Hawkins, A. R. (1986). The isolation and nucleotide sequence of the complex AROM locus of Aspergillus nidulans. Nucleic Acids Res 14, 2201-2213.

Geever, R. F., Huiet, L., Baum, J. A., Tyler, B. M. Patel, N. D.,
Rutledge, B. J., Case, M. E. \& Giles, N. H. (1989). DNA sequence, organisation and regulation of the qa gene cluster of Neurospora crassa. J Mol Biol 207, 15-34.

Grant, S., Roberts, C. F., Lamb, H. K., Stout, M. \& Hawkins, A. R. (1988). Genetic regulation of the quinic acid utilization $(q u t)$ gene cluster in Aspergillus nidulans. J Gen Microbiol 134, 347-358.

Grewe, R. \& Haendler, H. (1966). 5-Dehydroquinic acid. Biochem Prep 11, 21-26.

Hawkins, A. R. (1987). The complex arom locus of Aspergillus nidulans: evidence for multiple gene fusions and convergent evolution. Curr Genet 11, 491-498.

Hawkins, A. R. \& Lamb, H. K. (1995). The molecular biology of multidomain proteins. Selected examples. Eur J Biochem 232, 7-18.

Hawkins, A. R. \& Smith, M. (1991). Domain structure and interaction within the pentafunctional AROM polypeptide. Eur $J$ Biochem 196, 717-724.

Hawkins, A. R., Da Silva, A. J. \& Roberts, C. F. (1985). Cloning and characterisation of the three enzyme structural genes $q u t B, q u t C$ and qutE, from the quinic acid utilisation gene cluster in Aspergillus nidulans. Curr Genet 9, 305-311.

Hawkins, A. R., Lamb, H. K., Smith, M., Keyte, J. W. \& Roberts, C. F. (1988). Molecular organisation of the quinic acid utilisation (qut) gene cluster in Aspergillus nidulans. Mol \& Gen Genet 214, 224-231.

Hawkins, A. R., Lamb, H. K. \& Roberts, C. F. (1992). Structure of the Aspergillus nidulans qut repressor-encoding gene: implications for the regulation of transcription initiation. Gene 110, 109-114.

Hawkins, A. R., Lamb, H. K., Moore, J. D., Charles, I. G. \& Roberts, C. F. (1993a). The pre-chorismate (shikimate) and quinate pathways in filamentous fungi: theoretical and practical aspects. $J$ Gen Microbiol 139, 2891-2899.

Hawkins, A. R., Lamb, H. K., Moore, J. D. \& Roberts, C. F. (1993b). Genesis of eukaryotic transcriptional activator and repressor proteins by splitting a multidomain anabolic enzyme. Gene $\mathbf{1 3 6}$, 49-54.

Hawkins, A. R., Moore, J. D. \& Adeokun, A. M. (1993C). Characterization of the 3-dehydroquinase domain of the pentafunctional AROM protein, and the quinate dehydrogenase from Aspergillus nidulans and the overproduction of the type II 3 dehydroquinase from Neurospora crassa. Biochem J 296, 451-457.

Hawkins, A. R., Lamb, H. K., Radford, A. R. \& Moore, J. D. (1994). Evolution of transcription-regulating proteins by enzyme recruitment: molecular models for nitrogen metabolite repression and ethanol utilisation in eukaryotes. Gene 146, 145-158.

Kinghorn J. R. \& Hawkins, A. R. (1982). Cloning and expression in Escherichia coli $\mathrm{K}-12$ of the biosynthetic dehydroquinase function of the arom cluster gene from the eukaryote Aspergillus nidulans. Mol \& Gen Genet 186, 145-152.

Laemmli, U. K. (1970). Cleavage of structural proteins during assembly of the head of bacteriophage T4. Nature 227, 680-685.

Lamb, H. K., Hawkins, A. R., Smith, M., Harvey, I. J., Brown, J., Turner, G. \& Roberts, C. F. (1990). Spatial and biological characterisation of the complete quinic acid utilisation gene cluster in Aspergillus nidulans. Mol \& Gen Genet 223, 17-23.

Lamb, H. K., Bagshaw, C. R. \& Hawkins, A. R. (1991). In vivo overproduction of the pentafunctional AROM polypeptide in Aspergillus nidulans affects metabolic flux in the quinate pathway. Mol \& Gen Genet 227, 187-196.

(w/v) bovine serum albumin in rinse buffer $\left(137 \mathrm{mM} \mathrm{NaCl}, 1.5 \mathrm{mM} \mathrm{KH} \mathrm{PO}_{4}, 8 \mathrm{mM} \mathrm{Na}_{2} \mathrm{HPO}_{4}, 2.7 \mathrm{mM} \mathrm{KCl}, 0.5 \%\right.$, w/v, Tween 20) at $37{ }^{\circ} \mathrm{C}$ and processed for antibody detection (Samson, 1986) using rabbit antibody at a dilution of 1 in 50 . The gels to generate (b) and (c) were run simultaneously under the same conditions for the same length of time. 
Lamb, H. K., van den Hombergh, J. P. T. W., Newton, G. H., Moore, J. D., Roberts, C. F. \& Hawkins, A. R. (1992). Differential flux through the quinate and shikimate pathways: implications for the channeling hypothesis. Biochem J 284, 181-187.

Lamb, H. K., Moore, J. D., Lakey, J. H., Levett, L., Wheeler, K. A., Lago, H. Coggins, J. R. \& Hawkins, A. R. (1995). Comparative analysis of the QUTR transcription repressor protein and the three $\mathrm{C}$-terminal domains of the pentafunctional AROM enzyme. Biochem $J$ (in press).

Leuther, K. K., Salmeron, J. M. \& Johnston, S. A. (1993). Genetic evidence that an activation domain of GAL4 does not require acidity and may form a $\beta$-sheet. Cell 72, 575-585.

Mackay, K. Lund, A. M., Raghunath, M., Steinmann, B. \& Dalgleish, R. (1993). SSCP detection of a Gly 56 Val substitution in the Pro-alpha 1 (I) collagen chain resulting in osteogenesis imperfecta type II. Human Genet 91, 439-444.

Maniatis, T., Fritsch, E. F. \& Sambrook, J. (1982). Molecular Cloning: a Laboratory Manual. Cold Spring Harbor, NY: Cold Spring Harbor Laboratory.

Moore, J. D. \& Hawkins, A. R. (1993). Overproduction of, and interaction within, bi-functional domains from the amino and carboxy termini of the pentafunctional AROM protein of Aspergillus nidulans. Mol \& Gen Genet 240, 92-102

Moore, J. D., Lamb, H. K., Garbe, T., Servos, S., Dougan, G., Charles, I. G. \& Hawkins, A. R. (1992). Inducible overproduction of the Aspergillus nidulans pentafunctional AROM protein and the type I and II 3-dehydroquinases from Salmonella typhi and Mycobacterium tuberculosis. Biochem J 287, 173-181.

Moore, J. D., Hawkins, A. R., Charles, I. G., Deka, R., Coggins, J. R., Cooper, A., Kelly, S. \& Price, N. C. (1993). Characterisation of the type I dehydroquinase from Salmonella typhi. Biochem J 295, $277-285$.

Moore, J. D., Coggins, J. R., Virden, R. \& Hawkins, A. R. (1994). Efficient independent activity of a monomeric monofunctional dehydroquinase synthase derived from the $\mathrm{N}$-terminus of the pentafunctional AROM protein of Aspergillus nidulans. Biochem $J$ 301, 297-304.

Orita, M., Suzuki, Y., Sekiya, T. \& Hayashi, K. (1989). Rapid and sensitive detection of point mutations and DNA polymorphisms using the polymerase chain reaction. Genomics 5, 874-879.

Samson, A. C. R. (1986). Anomalous behaviour of Newcastle disease virus haemagglutinin-neuraminidase protein in western blotting analysis of monoclonal antibody binding sites. J Gen Virol 67, 1199-1203.

Sanger, F., Nicklen, S. \& Coulson, A. R. (1977). DNA sequencing with chain terminating inhibitors. Proc Natl Acad Sci USA 74, 5463-5467.

Sharrocks, A. D. (1994). A T7 expression vector for producing Nand $\mathrm{C}$-terminal fusion proteins with glutathione $S$-transferase. Gene 138, 105-108.

Studier, E. W., Rosenberg, A. H., Dunn, J. J. \& Dubendorf, J. W. (1990). Use of T7 RNA polymerase to direct expression of cloned genes. Methods Enzymol 185, 60-89.

Van den Hombergh, J. P. T. W., Moore, J. D., Charles, I. G. \& Hawkins, A. R. (1992). Overproduction in Escherichia coli of the dehydroquinate synthase domain of the Aspergillus nidulans pentafunctional AROM protein. Biochem J 284, 861-867.

Van Hoy, M., Leuther, K. K., Kodadek, T. \& Johnston, S. A. (1993). The acidic activation domains of the GCN4 and GAL4 proteins are not helical but form $\beta$-sheets. Cell 72, 587-594.

Whittington, H. A., Grant, S., Roberts, C. F. \& Hawkins, A. R. (1987). Identification and isolation of a putative permease gene in the quinic acid utilisation (qut) gene cluster of Aspergillus nidulans. Curr Genet 12, 135-139.

Received 5 June 1995; revised 13 September 1995; accepted 20 September 1995. 